УДК $81-22$

\title{
И.И. Кушакова
}

\section{ЛЕКСИЧЕСКАЯ И ФРАЗЕОЛОГИЧЕСКАЯ ПАРАДИГМАТИКА ФРАНЦУЗСКОГО ЯЗЫКА: MADELEINE DE PROUST}

Статья посвящена лингвокультурологическому анализу фразеологизма madeleine de Proust в coвременном французском языке на основе лексикографических данных, методом компонентного анализа и семантического анализа текста. В работе определяется степень идиоматичности изучаемого фразеологизма. Используя методику лингвокультурного декодирования, выявляются эмоционально-чувственная, этическая и эстетическая информации; архетипическая, мифологическая, религиозная, философская и научная информации, которые являются глубинными основаниями значения любого фразеологизма. Так во фразеологизме madeleine de Proust базисными типами информации стали религиозный и философский. Первый связан с внутренней формой многозначного слова madeleine. Оно является нарицательным именем - означает наименование мучного изделия и именем собственным - Мадлен именовали девушку, которая придумала данное кулинарное блюдо; это слово ассоциируется с образами Магдалины-грешницы и святой Марии-Магдалины, что отражено во фразеологической системе французского языка; с именем собственным Saint-Jacques, которое используется и для описания предмета материального мира, и сопровождает писателя в жизни, а героя - в романе. Философский тип информации, заключенный в слове, связан с размышлениями, знаками, философией Пруста, с понятиями произвольной и непроизвольной памяти. Творческим толчком к формированию полисемии слова послужила чувственноэмоциональная информация. Исследование показало, что полисемичное слово madeleine в семантическом пространстве художественного текста благодаря дарованию писателя, его эмоционально-чувственным переживаниям, его потоку сознания, расширило свой смысл и стало одним из компонентов новой языковой единицы: фразеологизма madeleine de Proust, в котором личностное индивидуально-коллективное сознание осуществило слияние материи и идеальной сущности в единое целое.

Ключевые слова: Пруст, прустовская мадлен, фразеологизм, лингвокультурологический анализ, идиоматика, логоэпистема, внутренняя форма слова.

DOI: 10.35634/2412-9534-2021-31-6-1204-1211

Целью нашей работы является лингвистический и экстралингвистический анализ процесса появления словосочетания madeleine de Proust; анализ перехода слова из материального мира в когнитивную сферу, или говоря словами А.Ф. Лосева, анализ иерархии интеллигентных самоутвержденностей [7, с. 31]. Лексическая единица madeleine, которая входит в номинативную структуру исследуемого фразеологизма, обозначает предмет материального мира - печенье. Возможно, что слово madeleine, обозначая печенье, так и осталось бы номинантом вкусного изделия французской кухни, если бы его не упомянул Марсель Пруст в своем романе «По направлению к Сванну» из цикла «В поисках утраченного времени». Это было началом интересного пути слова madeleine во фразеологическое словосочетание madeleine de Proust.

В современном французском языке словосочетание madeleine de Proust уже в 50-х гг. XX в. стало фразеологической единицей (ФЕ), линговкультуремой, зафиксированной во французских словарях. Этот фразеологизм обладает высокой степенью идиоматичности. Под идиоматичностью мы понимаем «полную или частичную невыводимость общего значения фразеологизма из значения составляющих его компонентов» [4, с. 298]. Приведем значение этого фразеологизма во французских толковых словарях: «objet qui déclenche des souvenirs en chaîne» [CNRTL].; «objet, odeur, saveur, etc., qui fait surgir une série de souvenirs anciens» [LR]; «objet qui déclenche des souvenirs en chaîne» [DAF], «sensation de nostalgie provoquée par une odeur, une couleur ou un lieu» [LIN]. Лексические значения слов madeleine u Proust абсолютно не отражаются во внутренней форме фразеологизма, которое имеет следующее значение: «что-то (ивет, запах, место и т.д.), что вызывает в памяти воспоминания прошлого». В определении значения нет упоминания ни Мадлен, ни Пруста. Только с грамматической точки зрения свободное словосочетание madeleine de Proust и фразеологизм madeleine de Proust имеют общий признак, это предлог de со значением «принадлежности». Раскрыв семантическое значение фразеологизма, мы прикоснулись к поверхностному уровню его структуры.

Однако каждый фразеологизм обладает также глубинными, культурно обусловленными основаниями его значения, «носителями постепенно накапливаемых в них следующих типов чувственной и 
Лексическая и фразеологическая парадигматика французского языка...

1205

интеллектуальной информации: эмоционально-чувственной, этической и эстетической информации; архетипической, мифологической, религиозной, философской и научной информации» $[5$, с. 310$]$. В таком же ключе рассматривается внутренняя форма языкового знака и в работах Н.Ф. Алефиренко: «...внутренняя форма не сводится ни к концепту, ни к эмосеме, ни к этимологическому значению. Это своего рода речемыслительный кентавр, фокусирующий в себе один из признаков этимологического образа, модально-оценочный элемент эмосемы и отдельные смысловые гены концепта» [2, с. 8-9].

В исследовании придерживаемся ономасиологического подхода, при котором выясняется связь вещного значения и характера его обозначения через призму культурно-исторических явлений. На основе лексикографических данных, методом компонентного анализа, семантического анализа текста проводим лингвокультурологическое декодирование значения ФЕ madeleine de Proust. Попытаемся раскрыть все виды информации, участвующие в формировании фразеологизма madeleine de Proust, используя методику лингвокультурологического декодирования разнородной культурной информации, содержащейся в глубинном основании фразеологизмов, разработанной И. В. Зыковой [5].

Исследование начинаем с анализа интеллектуальных типов, которые представлены архетипической, мифологической, религиозной, философской и научной информацией.

На основе анализа внутренней формы в значении ФЕ madeleine de Proust архетипический тип информации связан с понятиями «воспоминание»/ souvenirs, «прошлое»/ anciens, «душа»/ nostalgie, с теми необъяснимыми, неосязаемыми материями, которые не подаются рациональному объяснению, они необъяснимы, остаются в сфере чувств, ощущений, на уровне бессознательного. Можно охарактеризовать строками М. Пруста: "Un plaisir délicieux m'avait envahi, isolé, sans la notion de sa cause. ...J'avais cessé de me sentir médiocre, contingent, mortel. D'où avait pu me venir cette puissante joie? Je sentais qu'elle était liée au goût du thé et du gâteau, mais qu'elle le dépassait infiniment, ne devait pas être de même nature» [17, c. 66].

Мифологический тип информации связан с метафорическим мышлением человека, с одухотворением, с персонификацией объектов материального мира. В нашем случае обратимся сначала к словообразованию, к образованию слова madeleine. Несомненно, что печенье в форме ракушки, известное с конца 18 века, получило свое название в результате антономасии от имени собственного Madeleine. По одной из версий по имени изобретательницы рецепта - Мадлен Помье: «La recette de ce gâteau est attribuée par De La Reynière (v. Quem. DDL t. 20) à Madeleine Paumier, pensionnaire et ancienne cuisinière de Madame Perrotin de Barmond, dont on ne possède aucun renseignement précis» [CNRTL]. Во французском языке есть целый ряд слов, образованных таким видом метонимии и обозначающих продукты питания, кондитерские изделия в частности: madeleine, charlotte, tatin, richelieu, savarin, sandwish, dartois, battenberg, saint-honoré, gros Guillaume, sablé, biscuit de Savoie, pithiviers, génoise, Mont-Blanc, Paris-Brest, Forêt-Noire [10]. Можно сказать, что данный способ словообразования весьма продуктивен во французском языке в сфере номинации продуктов питания. Давно уже замечено, что «сущность номинации заключается не в том, что языковой знак обозначает вещь или каким-то образом соотносится с вещью, а в том, что он репрезентирует некоторую абстракцию как результат познавательной деятельности человека...любое собственное имя потенциально приложимо также к целому ряду предметов. Закрепление этой идеальной сущности в слове и есть лексическая номинация» [6, с. 2-13]. И история лексемы madeleine на этом не останавливается.

Религиозный тип информации значительно расширяет структуру исследуемого фразеологизма. Плодотворным источником этой информации является христианское вероучение, библейские сказания. Обратимся к лексической единице madeleine.

В словарях даются имеет следующие определения madeleine как продукта питания: «petit gâteau de forme ovale dont le dessus est renflé et strié et dont la pâte est moelleuse et délicatement parfumée» [CNRTL]; «petit gâteau en forme de coquille bombée, constitué d'une pâte à base d'œufs battus, de sucre, de farine, de beurre fondu, parfumée au citron ou à la fleur d'oranger» [LR]; «petit gâteau en forme de coquille dont la pâte est molle» [LIN].

Однако, слово madeleine во французском языке входить в состав нескольких фразеологических оборотов, где идет отсылка к имени собственному Магдалине, евангельской грешнице. Так выражение pleurer comme une madeleine означает «чрезмерно много плакать», une Madeleine - «кающаяся грешница». « [P. allus. à celle qui fut pardonnée par Jésus] Pécheresse repentante. Une Madeleine. Elle leva la tête en haut comme au ciel, et je vis ses grands yeux bleus mouillés comme ceux d'une Madeleine. Pendant qu'elle priait, il prenait le bout de ses longs cheveux et les baisait sans faire de bruit (VIGNY, Serv. et 
grand. milit., 1835, p. 44). Expr. fam. Pleurer comme une Madeleine. Pleurer à chaudes larmes, en abondance. Quand j'ai vu cela, j'ai pleuré comme une Madeleine (ROLLAND, J.-Chr., Révolte, 1907, p. 473).» [TLF]. Но летние сорта груш, винограда, персика называются madeleine уже в честь дня почитания Святой Марии- Магдалины: «BOT. Variété de fruits qui mûrissent à l'époque de la Sainte Madeleine. Poire, pêche Madeleine. P. ell. la Madeleine. Les cépages de table précoces peuvent intéresser l'amateur de toutes les régions de France (...). Peu de variétés sont réellement satisfaisantes. La plus belle, la Madeleine angevine (...) arrive à maturité environ dix jours avant le chasselas (Levadoux, Vigne,1961, p. 37) [CNRTL]. Существование двойного, диаметрального образа Магдалины Madeleine, характерного для французской культуры, также лежит в понимании фразеологизма madeleine de Proust.

Интересно, что изначально в черновиках к роману «По направлению к Сванну» Марсель Пруст выбирал между раin grillé (поджаренный хлеб) и bisscotte (гренок). "Il y a une maison de campagne où j'ai passé plusieurs étés de ma vie. Parfois je pensais à ces étés, mais ce n'étaient pas eux. [...] Et le hasard fit qu'elle m'apporta quelques tranches de pain grillé. Je fis tremper le pain grillé dans la tasse de thé, [...]et m'attachant toujours à ce bout de pain trempé qui semblait produire tant de merveilles, [...]Il y trempait une biscotte et me la donnait à manger. Et quand ces étés furent passés, la sensation de la biscotte ramollie dans le thé fut un des refuges où les heures mortes - mortes pour l'intelligence-allèrent se blottir»..[16, c. 212].

Можно предположить, что слова biscotte и pain grillé не стали бы фразеологизмами, лингвокультуремами французского языка, т.к. они просто обозначают предмет материальной культуры, который встречается у многих народов с идентичным названием. Другое дело слово madeleine, которое невозможно перевести на другие языки без соответствующих пояснений, т.к. во французской культуре оно имеет ассоциации с именем собственным Мадлен /Магдалина.

Вот отрывок из романа М. Пруста, в котором появляется слово madeleine: «Elle envoya chercher un de ces gâteaux courts et dodus appelés Petites Madeleines qui semblaient avoir été moulées dans la valve rainurée d'une coquille de Saint-Jacques.» [17, c. 66].

Читая один из переводов романа на русский язык, мы не встречаем ни слово мадлен, ни упоминание святого Иакова: «...мама велела принести одно из тех круглых, пышных бисквитных пирожных, формой для которых как будто бы служат желобчатые раковины пластинчатожаберных моллюсков...» [9, с. 41]. Это подтверждение того, что слово madeleine является безэквивалентной лексической единицей, следовательно, выражение madeleine de Proust является идиоматическим. В русской культуре слово «Мадлен» не имеет никаких культурно-значимых ассоциаций, являясь просто женским именем, а для французского сознания, тем более для талантливого писателя, слова madeleine, Saint-Jacques (une coquille de Saint-Jacques) имеют целый ряд взаимосвязанных ассоциаций. Так, une coquille de Saint-Jacques переводим как ракушка моллюска с названием Saint-Jacques, этот моллюск самый дорогой из всех используемых во французской кулинарии, продукт гурманов, относящийся к высокой кухне. С другой стороны, выпуклая раковина моллюска - это эмблема паломничества к могиле апостола Иакова (Saint-Jacques), который был рыбаком. Возникает двойная ассоциация: с материальным миром (формой печенье похоже на ракушку) и миром духовным (ощущение парения, благодати, неземного озарения, присущее людям святым). Еще одно интересное наблюдение: деревушка Комбре, описываемая в романе, это французская деревня Илье (Illiers, с 1971г. Illiers-Combray), в которой расположена знаменитая церковь Святого Иакова (l'église de Saint-Jacques), в романе - церковь Святого Илария, которой Прустом посвящено много восторженных строк, что подчеркивает ее важность в жизни писателя. Домик тетушки главного героя в романе находится на улице Сен-Жак (SaintJacques). Возникает целый ассоциативный ряд, уводящий в духовную сферу, когда автор прибегает к физическому описанию формы материального предмета.

В понимании ФЕ madeleine de Proust сложно отделить от религиозной информации эмоционально-чувственную. Это прежде всего информация о том, через какой «канал» восприятия осуществляется непосредственное или опосредованное постижение объекта, в качестве которого выступают различные органы чувств (органы зрения, слуха, обоняния, вкуса, осязания, восприятия гравитации и др.) [5, с. 326]. В отношении нашего предмета исследования такими каналами были зрительное восприятие и вкус. «Et dès que j'eus reconnu le goût du morceau de madeleine trempé dans le tilleul ...tout Combray et ses environs, tout cela qui prend forme et solidité, est sorti, ville et jardins, de ma tasse de thé» $[17$, c. 71$]$.

Описание печенья при помощи прилагательных courts (небольшие), petites (миленькие), dodus (пухленькие), moulées (вылитые, с четко-обрисованными формами), valve rainurée (рифлёная створка 
Лексическая и фразеологическая парадигматика французского языка...

1207

ракушки) - это эмоционально-чувственное описание предмет. По мнению исследователей, это аллюзия на образ женщины [14], и даже на образ матери героя [15]. И снова вспоминаем женское имя Мадлен/Магдалина. И автор снова отталкивается от материального предмета и переходит в эмоционально-чувственный мир.

Приведем еще один отрывок: «Et tout d'un coup le souvenir m'est apparu. [...] La vue de la petite madeleine ne m'avait rien rappelé avant que je n'y eusse goûté; [...]; les formes - et celle aussi du petit coquillage de pâtisserie, si grassement sensuel sous son plissage sévère et dévot - s'étaient abolies, ou, ensommeillées, avaient perdu la force d'expansion qui leur eût permis derejoindre la conscience» [17, c. 68].

Автор опять дает биполярное метафорическое описание объекта материальной культуры. Прилагательные sévère (строгий) и dévot (набожный) характеризуют внешнюю сторону, складчатый наряд печенья, словно описание одеяния монахини. А слово sensuel (чувственный) используется для описания внутренней стороны, то, что скрыто за оболочкой, как за одеждой.

И теперь становится понятным, откуда возникло это описание, эти ассоциации, этот образ - от названия печенья madeleine, так как само слово madeleine наделено этой двойственностью как в языке, так и в культуре Франции, о которой мы уже говорили: святая Мария- Магдалина и кающаяся грешница Магдалина.

Подобный прием, двойные ассоциации (предмет материальной культуры и чувственный образ женщины), Марсель Пруст использует и в отрывке описания девочки-подростка, дочки Вентейля: «...cette odeur comme sous les parties gratinées le goût d'une frangipane, ou sous leurs taches de rousseur

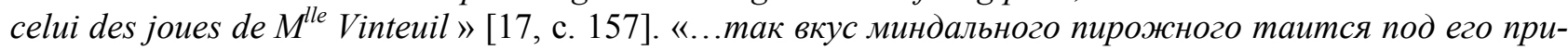
горелою корочкой и точно так же нежность щек дочки Вентейля скрывается под веснушками» $[9$, c. 99].

Именно зрительное восприятие, описание внешнего вида печенья связало два образа Мадлен/Магдалины. А вкус породил философские размышления, что в итоге стало самым значимым типом информации в структуре фразеологизма madeleine de Proust. При формировании ФЕ эмоции, мысли, чувства передаются так, как будто мы их постигаем зрительно: вижу - значит это существует.

Источником философского типа информации в значении madeleine de Proust являются учения Платона и Аристотеля, оказавшие значительное влияние на формирование европейского мировоззрения, учение о припоминании (réminiscence) в частности. Согласно Платону предметы чувственного мира служат для возбуждения души. Аристотель говорит о способности человека сознательно вызывать воспоминания. Посмотрим определения слова réminiscence в словаре: «1. [Chez Platon] Souvenir d'une connaissance acquise dans une vie antérieure, quand l'âme, qui vivait dans le monde supra-sensible des essences, contemplait les Idées. 2. [Chez Aristote] Faculté de rappeler volontairement les souvenirs (Lal. 1968). Synon. mémoire volontaire (v. mémoire)» [CNRTL].

И в рамках философского типа информации, которая хранится в структуре ФЕ madeleine de Proust и отражена в его номинативной структуре, также лежат и занимают главенствующую роль подробные размышления Пруста о возникновении образов прошлого, о причинах, о значимости, о влиянии этих явлений. Пруст сам использует слово припоминание/ réminiscence: " qu'il s'agît (...) de réminiscences comme celle de l'inégalité des deux marches ou le goût de la madeleine, il fallait tâcher d'interpréter les sensations comme les signes d'autant de lois et d'idées...» [18, с. 22]. В интервью в 1913г. Пруст говорит следующее: «Mon œuvre est dominée par la distinction entre la mémoire involontaire et la mémoire volontaire» (в моем произведении главное - это анализ различия между произвольной и непроизвольной памятью (перевод наш)) [Цит. по 19]. И писатель указывает на «мадлен» как лучший наглядный пример его измышлений.

Сегодня уже используется такое понятие как la réminiscence proustienne (прустовское припоминание), которое не идентично платоновскому понятию. Так исследователи выделяют следующее значимое отличие: «la reconnaissance ne se fonde pas sur la vision préalable de la vraie réalité. Au contraire, on pourrait dire qu'elle la crée» / «узнавание не основывается на предварительном видении существующей реальности. Наоборот, можно было бы даже сказать, что оно ее создает» (перевод наш) $[13$, c. 22-23]. В этом же ключе Пруста сравнивают с импрессионистами, объединяя их общим творческим вектором: от впечатления к выражению [13].

Использование имени Proust в образовании ФЕ прямо указывает на значимость этой личности во французской культуре, в ее влиянии на ментальность других людей. Следовательно, поиск глу- 
бинной информации для раскрытия значения фразеологизма madeleine de Proust в словах, в мыслях автора правилен и необходим.

Наконец последний тип интеллектуальной информации - это научная информация, содержащаяся в глубинном образе фразеологической единицы madeleine de Proust. Она отражает специфику научной формы осмысления мира, в частности феномена памяти, исследуемого психологами, нейрофизиологами и другими специалистами. В настоящее время даже в научно-популярных статьях о психологии и т. п. можно встретить фразеологизм madeleine de Proust: «Petit à petit, les grands singes révèlent en eux bien des capacités qu'on croyait réservées à l'homme, celle de rire, celle d'avoir des relations sexuelles «ludiques» sans but de reproduction, celle de se faire la guerre... Et l'on découvre désormais qu'eux aussi ont leur madeleine de Proust» [11].

Последний тип чувственной информации - это этическая и эстетическая информация. Она «определяет культурную ценность (в том числе высшую) описываемого в образе объекта, его культурную значимость; дает культурную установку на определенное к нему отношение, формируя «сердцевину» коннотативного потенциала фразеологизма» [5, с. 330]. Во-первых, в исследуемом фразеологизме эта информация связана с именем Марселя Пруста, всемирно известного писателя, с его талантом, с его влияние на литературу. Если имя собственное попало в культурную память, значит оно имеет определенную ценность для того или иного сообщества, т.е. его стоит или необходимо запомнить. Это свидетельствует о еще одной характерной черте культурной памяти, выделенной Ю.М. Лотманом, - о ее селективности [8]. Во-вторых, предмет материальной культуры перешел в духовную сферу, стал обозначать абстрактное существительное «воспоминание» с богатым ассоциативным рядом. Слово madeleine в романе Пруста становится знаком мира впечатлений и чувственных свойств.

Случается, что некое чувственно воспринятое свойство одаривает нас несказанной радостью и, одновременно, передает нам что-то вроде безусловного требования. Испытанное и воспринимаемое таким образом свойство проявляется уже не как нечто, принадлежащее предмету, в котором оно актуализировалось, но как знак всех других предметов, которые мы должны постараться ценой напряжения расшифровать, всегда рискуя потерпеть неудачу [8, с. 38].

Можно привести из романа целый ряд примеров такого рода - колокольни, деревья, салфетка, ботинок и т.д. Но какими бы не были эти примеры, именно слово madeleine выходит за пределы романа и формирует новую языковую единицу французского языка madeleine de Proust. «La madeleine de Proust, porteuse du temps perdu peut être prise comme paradigme du passage de la sensation immédiate à la sensation esthétique - par laquelle devient alors possible une certaine maîtrise affective du réel qui est à l'opposé de la captation physique opérée par les espaces virtuels» / «Выражение madeleine de Proust, носитель потерянного времени, может рассматриваться как пример/образец перехода от чувственного ощущения к эстетическому ощущению, благодаря чему становится возможным определенный эмоциональный контроль над реальностью, в противовес физическому влиянию на нас нашей виртуальной памяти» (перевод наш) [12].

Для характеристики данного типа информации приведем также факт экстралингвистического порядка. Во французском фильме Люка Бессона «Перевозчик»/ «Le transporteur» героиня (не француженка) из всего многообразия рецептов в кулинарной книге выбирает печенье «мадлен» и готовит его главному герою. И это неслучайный эпизод. В фильме эта сцена служит герою толчком для дальнейших действий. Подобные межсемиотические транспозиции (перенос некоего содержания из одной семиотической среды в другую), усиливают значение фразеологического знака, подчеркивают его значимость для определенной культурной общности.

В заключении необходимо подчеркнуть, что в формировании значения фразеологизма все типы культурной информации находятся в тесном взаимодействии, при котором один из типов культурной информации, создавая предпосылки для формирования другого типа, одновременно связан или соотносится со всеми остальными типами культурной информации.

Так во фразеологизме madeleine de Proust базисными типами информации являются религиозный тип (связан с внутренней формой слова madeleine, с его многозначностью, с его фразеологической парадигматикой; с именем собственным Saint-Jacques, которое используется и для описания печенья, и сопровождает писателя в жизни, а героя - в романе) и философский тип (связан с размышлениями, знаками, философией Пруста, с понятиями произвольной и непроизвольной памяти), а толчком всему послужила чувственно-эмоциональная информация. Исследуемый фразеологизм можно 
назвать логоэпистемой согласно Н.Ф Алефиренко как «языковое отражение закрепленного общественной культурной памятью следа отраженной действительности в общественном сознании людей в результате постижения ими духовных ценностей» [1, с. 7].

Итак, полисемичное слово madeleine в семантическом пространстве художественного текста благодаря дарованию писателя, его эмоционально-чувственным переживаниям, его потоку сознания, расширило свой смысл и стало одним из компонентов новой языковой единицы. Можно сказать, что во фразеологизме madeleine de Proust личностное индивидуально-коллективное сознание осуществило слияние материи и идеальной сущности в единое целое.

\section{СПИСОК ИСТОЧНИКОВ И ЛИТЕРАТУРЫ}

1. Алиференко Н.Ф. Фразеологические логоэпистемы: архетипы и символы // Научные ведомости БелГУ. 2014. Выпуск 22. Серия: Гуманитарные науки. № 13 (184). С.7-14

2. Алиференко Н.Ф. Когнитивно-семасиологическое содержание языкового знака // Вестник ТГПУ, 2005. Выпуск 3(47). Серия: Гуманитарные науки (филология). С.5-10.

3. Делез Ж. Марсель Пруст и знаки. Статьи. Перев. с франц. Е. Г. Соколова. СПб: Алетейя, 1999. 190 с.

4. Жуков В.П. Идиоматичность фразеологизма в сопоставлении с идиоматичностью слова // В.П. Жуков. Избранные работы по русскому языку. Жуков А. В. (ред.). Великий Новгород: НовГУ, 2011. С. 297-308.

5. Зыкова И.В. Роль концептосферы культуры в формировании фразеологизмов как культурноязыковых знаков: дис. ... док. наук. Москва, 2014. 510 с.

6. Колшанский Г.В. Некоторые вопросы семантики языка в гносеологическом аспекте // Принципы и методы семантических исследований. В.Н. Ярцева (ред.). Москва: Наука, 1976. С. 5-31.

7. Лосев А.Ф. Философия имени / Самое само: Сочинения. М.: ЭКСМО-Пресс, 1999. 1024 с. С. 29-204.

8. Лотман Ю.М. Семиосфера. СПб: Искусство СПБ, 2001. 704 с.

9. Пруст М. По направлению к Свану: Пер. с фр. М. В. Толмачева. М.: Республика, 1992. 368 с.

10. Степанова И.И. Номинация мучных изделий в современном французском языке (лингвокультурологический аспект): дис. ... канд. наук. СПб., 2004. 209 с.

11. Barthélémy P. Les singes aussi ont leur madeleine de Proust / Le Monde [Electronic source]. 2013. URL: http://passeurdesciences.blog.lemonde.fr/2013/07/28/memoire-singes-madeleine-de-proust-cerveau. (дата обращения: 17.01.2021).

12. Durand A. L'épisode de la «madeleine» dans «À la recherche du temps perdu» [Электронный pecypc] / A. Durand. 2009. URL: https://www.comptoirlitteraire.com. (дата обращения: 17.01.2021).

13. Geneviève Henrot Sostero. De l'impression à l'expression: stylèmes du suspens(e) chez Proust. Modèles linguistiques. 2018, 4. Pp. 79-104.

14. Lejeune P. Écriture et Sexualité // revue «Europe», février-mars 197. [Электронный pecypc] / P. Lejeune. 1971. URL: https://www.autopacte.org/Petite_Madeleine.html. (дата обращения: 17.01.2021).

15. Meguro Junko. La nourriture chez Marcel Proust. Thèse de doctorat Langue, littérature et civilisation françaises.Université Sorbonne nouvelle. Paris 3 ed 120. Littérature française et comparée EA 3423. Centre de Recherche sur les Poétique du XIXe siècle Centre d'Études Proustiennes de Paris 3. 2015. 411 p.

16. Proust M. Contre Sainte-Beuve dans Contre Sainte-Beuve, précédé de Pastiches et mélanges et suivi de Essais et articles, édition établie par Pierre Clarac avec la collaboration d'Yves Sandre. Paris: Gallimard, Bibliothèque de la Pléiade, 1971. $1040 \mathrm{p}$.

17. Proust M. Du côté de chez Swann (1) (À la recherche du temps perdu). Paris: Gallimard. 251 p.

18. Proust M. Temps retrouvé. Paris : Gallimard, 1927.230 p.

19. Reymond P. Proust. La recherche du Temps perdu et la Madeleine [Электронный pecypc]. 2016. URL: www.pierre-reymond.fr/.../wp.../Proust-et-la-Madeleine.docx. (дата обращения: 17.01.2021).

20. Ricard M.-A. (Université Laval) Proust et le nouveau : une lecture anti-platonicienne de son œuvre // Symposium. 2012, 16 (1), Spring/Printemps. P.3-27.

\section{СПИСОК СЛОВАРЕЙ}

CNRTL - Centre National de Ressources Textuelles et Lexicales. [Электронный pecypc]. URL: http://www.cnrtl.fr (дата обращения: 17.01.2021).

DAF - Dictionnaire de l'Académie française, neuvième edition Version informatisée [Электронный pecypc]. URL: http://www.academie-francaise.fr/le-dictionnaire/la-9e-edition (дата обращения: 17.01.2021).

LIN - DICTIONNAIRE FRANÇAIS [Электронный pecypc]. URL: https://www.linternaute.fr/dictionnaire/fr (дата обращения: 17.01.2021).

LR - LAROUSSE [Электронный ресурc]. URL: www.larousse.fr (дата обращения: 17.01.2021). 
TLFi - Trésor de la langue Française informatisé [Электронный ресурc]. URL: http://www.atilf.fr/tlfi. (дата обращения: 17.01.2021).

Поступила в редакцию 25.02.2021

Кушакова Ирина Ивановна, кандидат филологических наук, доцент кафедры немецкого и романских языков, НОУ ВПО «Санкт-Петербургский гуманитарный университет профсоюзов» 192238, Россия, г. Санкт-Петербург, улица Фучика, 15 E-mail: step_ir@mail.ru

\title{
I.I. Kushakova \\ LEXICAL AND PHRASEOLOGICAL PARADIGMATICS OF THE FRENCH LANGUAGE: MADELEINE DE PROUST
}

\author{
DOI: $10.35634 / 2412-9534-2021-31-6-1204-1211$
}

The article is devoted to the linguocultural analysis of the idiom madeleine de Proust in modern French. The analysis is based on lexicographic data, component analysis method and text semantic analysis. Using the method of linguocultural decoding they find out emotional and sensual, ethical, aesthetic informations; archetypal, mythological, religious, philosophical and scientific informations, which are the deep foundations of the meaning of a phraseological unit. In the unit madeleine de Proust, the basic types of information are religious and philosophical. The first is associated with the polysemantic inner form of the word Madeleine. It is a nominative name - it means the name of a flour product and a proper name - Madeleine was the name of the girl who invented this culinary dish; this word is associated with the images of Magdalen-sinner and St. Mary-Magdalene, which is reflected in the phraseological system of the French language; with proper name Saint-Jacques, which is used to describe the subject of the material world, and accompanies the writer's life, the hero in the novel. The philosophical type of information is associated with Proust's reflections, signs, philosophy, with the concepts of the voluntary and involuntary memory. And all these were pushed by the sensual-emotional information. The polysemous word madeleine in the semantic space of the literary text thanks to the talent of the writer, his emotional and sensual experiences, his stream of consciousness, expanded its meaning and became one of the components of the new language unit madeleine de Proust.

Keywords: Proust style, Proust's Madeleine, idiom, linguocultural analysis, idiomatics, logo episteme, word's inner form.

\section{REFERENCES}

1. Aliferenko N.F. Frazeologicheskie logoe pistemy`: arxetipy` i simvoly` [Phraseological logosystems: archetypes and symbols] // Nauchny`e vedomosti BelGU [Scientific statements of Belgorod State University], 2014. Vy`pusk [Edition] 22. Seriya: Gumanitarny`e nauki [Series: Humanities]. № 13 (184). P. 7-14. (In Russian).

2. Aliferenko N.F. Kognitivno-semasiologicheskoe soderzhanie yazy kovogo znaka [Cognitive-semasiological content of a linguistic sign] // Vestnik TGPU [Bulletin of Tomsk State University ], 2005. Vy`pusk [Edition] 3 (47). Seriya: Gumanitarny`e nauki (filologiya) [Series: Humanities (philology)]. P. 5-10. (In Russian).

3. Deleuze G. Marsel' Prust i znaki [Proust et les signes]. Stat'I [Articles]. Transl. from French by E. Sokolova. SaintPetersburg: Aletejya, 1999. 190 p. (In Russian).

4. Zhukov V.P. Idiomatichnost' frazeologizma v sopostavlenii s idiomatichnost'yu slova. [Idiomatic phraseologism in comparison with the idiomatic words] In V.P. Zhukov. Izbrannye raboty po russkomu yazyku [Selected works on the Russian language]. Zhukov A.V. (red.). Velikij Novgorod: NovGU, 2011. Pp. 297-308. (In Russian).

5. Zykova I.V. Rol' konceptosfery kul'tury v formirovanii frazeologizmov kak kul'turnoyazykovyh znakov [The role of the conceptosphere of culture in the formation of phraseological units as culturally linguistic signs]: dis. ... dok. Nauk [Diss. of the doc. of philol. sciences]. Moscow, 2014. 510 p. (In Russian).

6. Kolshanskij G.V. Nekotorye voprosy semantiki yazyka v gnoseologicheskom aspekte. [Some questions of the semantics of the language in the gnoseological aspect] In: Principy i metody semanticheskih issledovanij [Principles and methods of semantic teachings]. V.N. Yarceva (red.). Moscow: Nauka, 1976. Pp. 5-31. (In Russian.)

7. Losev A.F. Filosofiya imeni / Samoe samo: Sochineniya [Name philosophy / The very essence: Essays]. Moscow: E’KSMO-Press, 1999. 1024 p. Pp. 29-204. (In Russian).

8. Lotman Yu.M. Semiosfera [Semiosphere]. Saint-Petersburg: Iskusstvo SPB, 2001. 704 p. (In Russian). 
9. Proust M. Po napravleniyu k Svanu: Per. s fr. M.V. Tolmacheva [Swann's Way: Transl. from French by M. Tolmacheva]. Moscow: Republic,1992. 368p. (In Russian).

10. Stepanova I.I. Nominaciya muchnyh izdelij v sovremennom francuzskom yazyke (lingvokul'turologicheskij aspekt) [Nomination of flour products in modern French (linguistic and cultural aspect]: dis. ... kand. nauk [Diss. of the cand. of philol. sciences]. Saint-Petersburg, 2004. 209p. (In Russian)

11. Barthélémy P. Les singes aussi ont leur madeleine de Proust / Le Monde [Electronic source]. 2013. URL: http://passeurdesciences.blog.lemonde.fr/2013/07/28/memoire-singes-madeleine-de-proust-cerveau. (Accessed: 17.01.2021).

12. Durand A. L'épisode de la «madeleine» dans «À la recherche du temps perdu» [Electronic source] / A. Durand. 2009. - URL: https://www.comptoirlitteraire.com (Accessed: 17.01.2021).

13. Geneviève Henrot Sostero. De l'impression à l'expression: stylèmes du suspens(e) chez Proust. Modèles linguistiques. 2018, 4. Pp. 79-104.

14. Lejeune P. Écriture et Sexualité //revue «Europe», février-mars 197. [Electronic source] / P. Lejeune. - 1971. URL: https://www.autopacte.org/Petite_Madeleine.html. (Accessed: 17.01.2021).

15. Meguro Junko. La nourriture chez Marcel Proust. Thèse de doctorat Langue, littérature et civilisation françaises.Université Sorbonne nouvelle - Paris 3 ed 120 - Littérature française et comparée EA 3423 - Centre de Recherche sur les Poétique du XIXe siècle Centre d'Études Proustiennes de Paris 3 -2015. 411p.

16. Proust M. Contre Sainte-Beuve dans Contre Sainte-Beuve, précédé de Pastiches et mélanges et suivi de Essais et articles, édition établie par Pierre Clarac avec la collaboration d'Yves Sandre. Paris : Gallimard «Bibliothèque de la Pléiade», 1971. $1040 \mathrm{p}$.

17. Proust M. Du côté de chez Swann (1) (À la recherche du temps perdu). Paris: Gallimard. 251p.

18. Proust M. Temps retrouvé. Paris: Gallimard, 1927. 230 p.

19. Reymond P. Proust. La recherche du Temps perdu et la Madeleine [Electronic source]. 2016. URL: www.pierrereymond.fr/.../wp.../Proust-et-la-Madeleine.docx. (Accessed: 17.01.2021).

20. Ricard M.-A. (Université Laval) Proust et le nouveau : une lecture anti-platonicienne de son œuvre// Symposium. 2012,16 (1), Spring/Printemps. Pp. 3-27.

Received 25.02.2021

Kushakova I.I., Candidate of Philology, Associate Professor at Department German and Romance languages Saint-Petersburg University of the Humanities and the trade unions

Futchika st. 15, Saint-Petersburg, Russia, 192238

E-mail: step_ir@mail.ru 